\title{
Correction to: Water resources of Balochistan, Pakistan—a review
}

\author{
Malik Muhammad Akhtar ${ }^{1} \cdot$ Abida Dost Mohammad ${ }^{1} \cdot$ Muhsan Ehsan $^{2} \cdot$ Rabia Akhtar $^{3} \cdot$ Jalil ur Rehman $^{3} \cdot$ \\ Zaira Manzoor ${ }^{4}$
}

Published online: 30 March 2021

(C) Saudi Society for Geosciences 2021

\section{Correction to: Arabian Journal of Geosciences (2021) 14:289 https://doi.org/10.1007/s12517-021-06502-y}

The original version of this paper was published with error. The Government of Pakistan published a new political map which the authors', unfortunately, forget to incorporate in this paper. According to Pakistan law it is forbidden to publish pervious map. So, it is requested to replace Fig. 1 with the new figure on an urgent basis.

The original article has been corrected.

The online version of the original article can be found at https://doi.org/ $10.1007 / \mathrm{s} 12517-021-06502-\mathrm{y}$

Malik Muhammad Akhtar drmalikma21@gmail.com

1 Department of Environmental Science, Faculty of Life Sciences \& Informatics, Balochistan University of Information Technology, Engineering and Management Sciences, Quetta 87300, Pakistan

2 Department of Earth and Environmental Sciences, Bahria University, Islamabad, Pakistan

3 Balochistan University of Information Technology, Engineering \& Management Sciences, Quetta 87300, Pakistan

4 Centre of Economics Research, Shandong University Central Campus, Jinan, China 


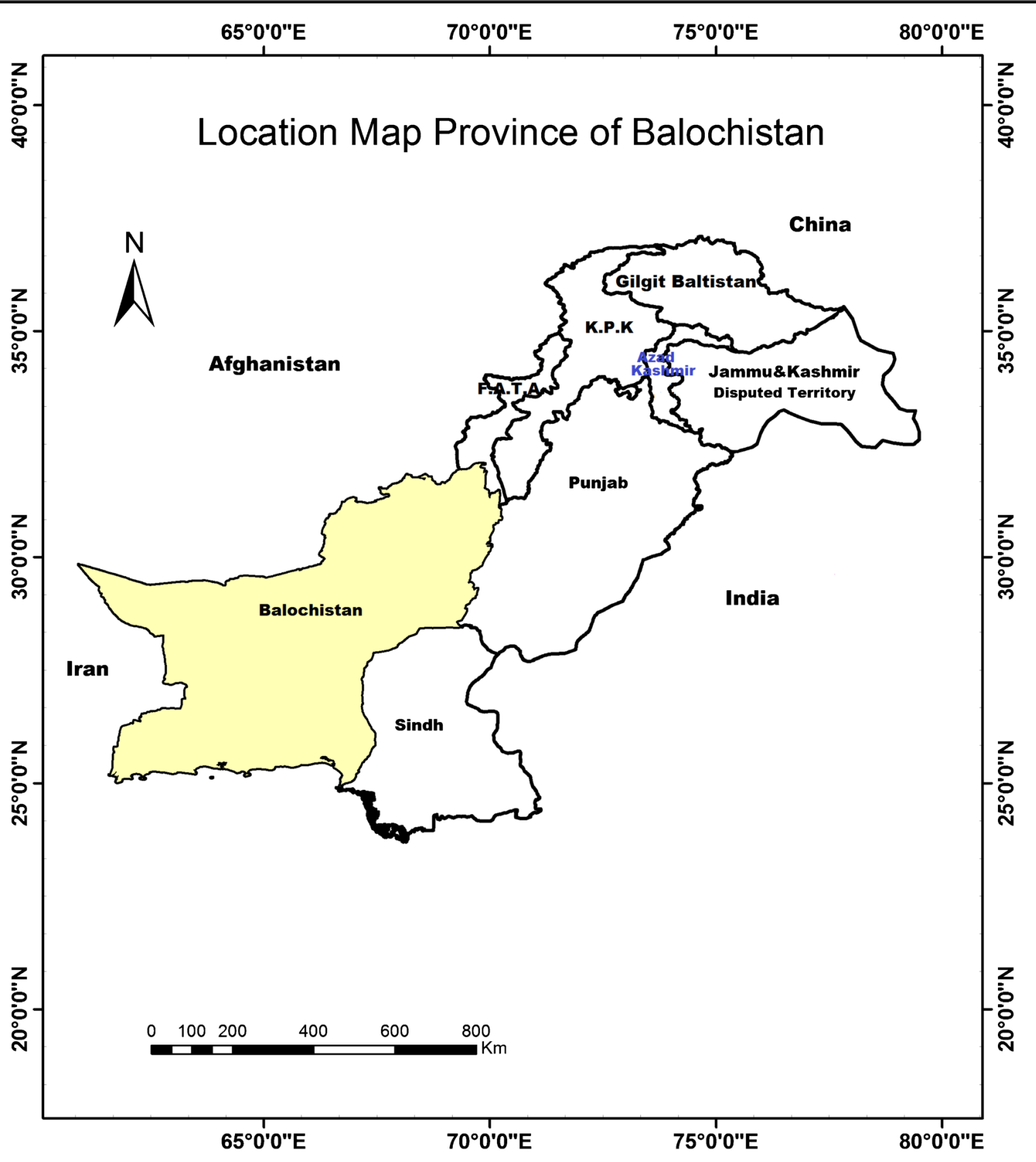

